\title{
Statistical Estimation of the Seismicity Level Change around Hokkaido, Northern Japan
}

\author{
Petr Voropaev, ${ }^{1}$ Hiroaki Takahashi, ${ }^{2}$ and Vadim Saltykov ${ }^{1}$
}

\begin{abstract}
The temporal seismicity change in two seismically active zones around Hokkaido, northern Japan was investigated using the statistical estimate of the seismicity level (SESL'09) procedure. Hypocenter data provided by the Japan Meteorological Agency from 1960 to 2013 were analyzed. The seismicity of two geographically different zones, formed by Pacific Plate subduction and Amurian Plate convergence, showed different statistical characteristics. Low cross-correlation values between the two zones also suggest independent seismic processes for each area. However, an anomalously high cross-correlation period was identified from 1996 to 2000, with a time lag of 8 weeks. A 6-month seismic quiescence period before the strongest Hokkaido Toho-Oki Earthquake (4 October 1994, $M_{\mathrm{j}}$ 8.2) was observed on the Pacific side.
\end{abstract}

Key words: Hokkaido, seismicity, SESL'09, seismic process, seismic quiescence.

\section{Introduction}

Hokkaido is a seismically active region related to Pacific Plate subduction on the southern (Pacific) side and Amurian Plate convergence on the western (Japan Sea) side (Fig. 1). The Japan Meteorological Agency (JMA) determined more than 180,000 earthquakes in total, including 13 with magnitude of $M_{\mathrm{j}}>7.0$, from 1960 to 2011. Significant seismic subduction activity, including 12 events with magnitude $M_{\mathrm{j}}>7$, associated with the subducting Pacific Plate, has been observed off the coast of southern Hokkaido. Typical interplate events, such as the 1973 Nemuro-Oki $\left(M_{\mathrm{j}} 7.4\right)$ and 2003 Tokachi-Oki $\left(M_{\mathrm{j}} 8.0\right)$ earthquakes, have occurred along the plate interface. In addition, intraslab earthquakes, such as the 1994 Hokkaido Toho-Oki $\left(M_{\mathrm{j}} 8.2\right)$ earthquake, have been observed in the region (Fig. 1).

An independent seismically active zone off the coast of western Hokkaido (eastern Japan Sea margin), formed by interaction between the North American and westward Amurian plates, has been identified. The earthquakes in this seismic belt occurred at depths shallower than the continental Moho. Large crustal earthquakes (e.g., 1983 Nihonkai-Chubu, $M_{\mathrm{j}}$ 7.7; 1993 Hokkaido Nansei-Oki, $M_{\mathrm{j}}$ 7.8) might reflect the active tectonics in this region (Fig. 1). The relatively higher seismicity level on the Pacific side compared with the Japan Sea side is caused by the plate convergence speed of $9 \mathrm{~cm} /$ year for the Pacific versus 1-2 cm/year for the Japan Sea side (Sella et al. 2002). The difference in the tectonic background and seismicity level between the Pacific and Japan Sea side might lead to interesting characteristics with respect to the temporal seismicity level change.

The time evolution of the regional seismic activity level has been previously investigated using several analysis methods (e.g., Ogata and Abe 1991; Wiemer and Wyss 1994; Saltykov and Kugaenko 2000). Several prior studies reported possible seismicity changes related to the alertness to great earthquakes. In this paper, we propose to use the new statistical estimates of the seismicity level (SESL'09) method, which offers an intuitive scale to describe the state of seismicity using an appropriate mathematical procedure. The regional seismicity of Hokkaido from 1960 to 2013 was analyzed using the SESL'09 method.

\section{Data and Method}

1 Kamchatkan Branch of Geophysical Survey of Russian Academy of Sciences, Boulevard Pipa 9, Petropavlovsk-Kamchatskii, Russia. E-mail: chicoli@emsd.ru

2 Hokkaido University, Kita 8, Nishi 5, Kita-ku, Sapporo, Japan. E-mail: hiroaki@sci.hokudai.ac.jp

\subsection{Hypocenter Catalog}

We used the hypocenter catalog of the JMA from January 1960 to October 2013. Two seismically 


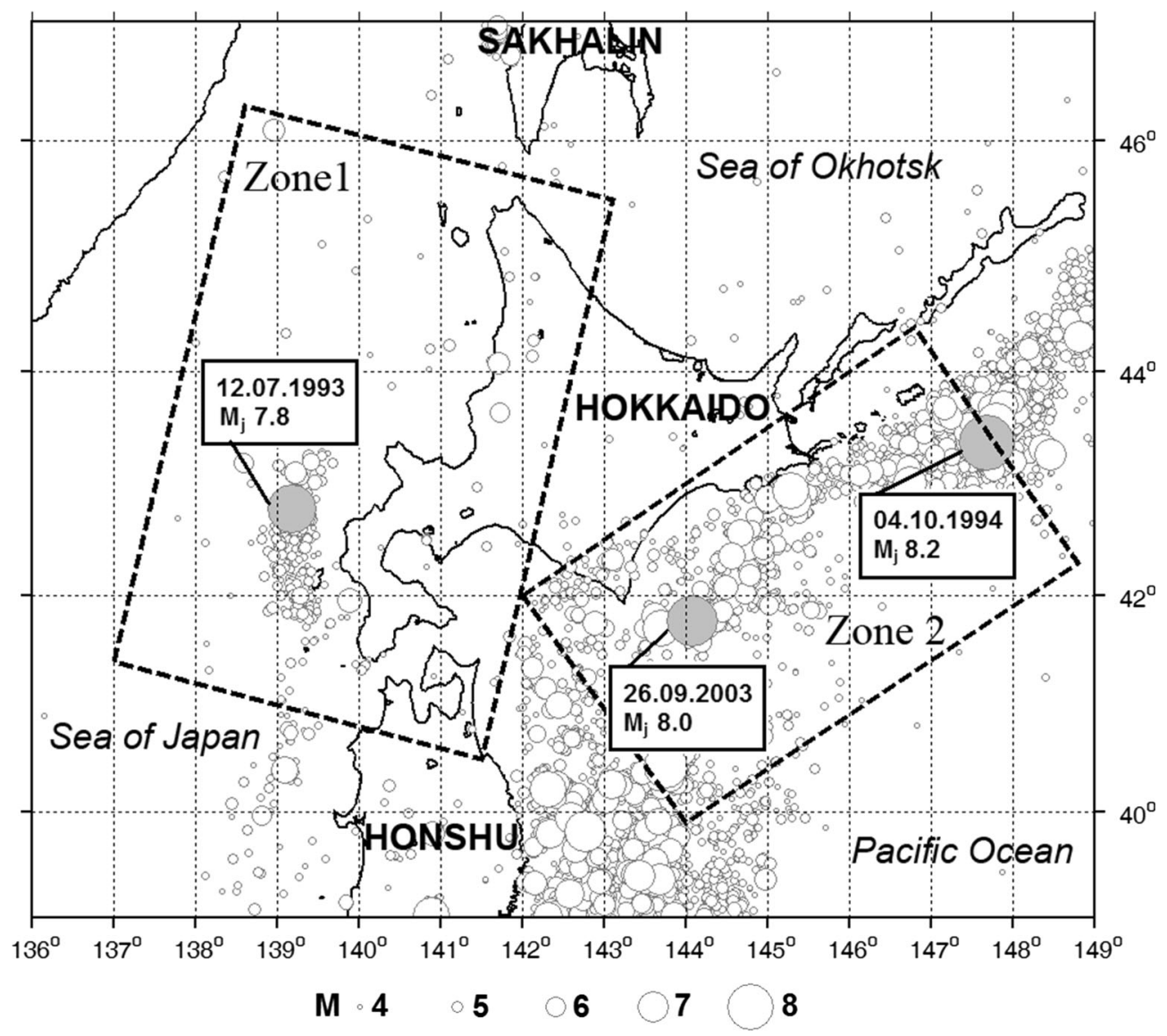

Figure 1

Seismicity of Hokkaido area for period 1990-2013 in depth range of 0-60 km. The studied zones are marked by dashed rectangles

active zones were selected for the study, considering their tectonic structures (Bird 2003; DeMets et al. 2010; Sella et al. 2002; Zonenshain and Savostin 1981) and recent seismicity (Fig. 1): zone 1 (Japan Sea side) is the western area that belongs to the Sea of Japan, and zone 2 (Pacific side) is the eastern area associated with subduction of the Pacific Plate. Earthquakes were selected in the depth range of 0-40 and 0-60 km for zone 1 and 2, respectively. The deeper range for zone 2 reflects the Pacific Plate subduction.

The seismicity of these two zones has different characteristics. Much stronger $(M \geq 7.0)$ earthquakes occur in zone 2 than in zone 1; only two earthquakes with magnitude $>7.0$ were recorded in zone 1 between 1960 and 2013. During this period, 13 earthquakes with $M_{\mathrm{j}} \geq 7.0$ and two earthquakes with $M_{\mathrm{j}} \geq 8.0$ (Hokkaido Toho-Oki, 4 October 1994, $M_{\mathrm{j}}=8.2$; Tokachi-Oki, 26 September 2003, $M_{\mathrm{j}}=8.0$ ) occurred in zone 2 . The difference in the moment release rate is caused by the plate convergence speed of $1-2 \mathrm{~cm}$ in zone 1 between the Amurian and North American plates versus $9 \mathrm{~cm}$ in zone 2 between the Pacific and North American plates (Sella et al. 2002). The earthquakes in zone 1 occurred within the crust, while the earthquakes in zone 2 involve interplate and intraslab events.

To obtain a homogeneous dataset, time periods with different cutoff magnitudes were defined for both zones using the Gutenberg-Richter relationship (Table 1). The magnitude in the JMA catalogs $\left(M_{\mathrm{j}}\right)$ was defined by the original JMA method. The calculation of the seismic moment $M_{0}$ from the 
Table 1

Parameters of earthquake data for territory of Hokkaido

\begin{tabular}{lllr}
\hline Zone & Sampling period & $\begin{array}{l}\text { Minimum homogeneity } \\
\text { magnitude }\left(M_{\mathrm{j}}\right)\end{array}$ & $\begin{array}{l}\text { Number of earthquakes } \\
\text { in sample }\end{array}$ \\
\hline \multirow{2}{*}{ Zone 1} & January 1960-October 2013 & 4.0 & 1010 \\
& January 1980-October 2013 & 3.5 & 2452 \\
& January 1985-October 2013 & 3.0 & 5344 \\
& January 1995-October 2013 & 2.5 & 6809 \\
\multirow{2}{*}{ Zone 2} & January 2001-October 2013 & 2.0 & 9104 \\
& January 1960-October 2013 & 4.5 & 2549 \\
& January 1980-October 2013 & 4.0 & 3846 \\
& January 1985-October 2013 & 3.5 & 7728 \\
& January 1995-October 2013 & 3.0 & 11,293 \\
\end{tabular}

JMA magnitude $M_{\mathrm{j}}$ is based on the relationship reported in Gusev and Mel'nikova (1990):

$$
\begin{aligned}
& \text { for } M_{\mathrm{j}}<6.8: \log \left(M_{0}\right)=1.32 \times M_{\mathrm{j}}+10.43 \text {, } \\
& \text { for } M_{\mathrm{j}} \geq 6.8: \log \left(M_{0}\right)=0.69 \\
& \quad \times\left(M_{\mathrm{j}}\right) 2-7 \times M_{\mathrm{j}}+41.94
\end{aligned}
$$

\subsection{SESL'09 Methodology}

Several parameters are used to characterize the seismicity in a specific region within a predefined time interval, e.g., the total energy of earthquakes $E$, number of earthquakes $N$, activity rate $A$, and the slope of the recurrence curve $b$ based on the Gutenberg-Richter law (Gutenberg and Richter 1949).

The $b$ value is a parameter that describes the relative amount of shocks ranging from large to small ones. The commonly used $b$ value is determined by a linear fit based on maximum-likelihood estimation (Aki 1965). Assessment of the $b$-value space and temporal variations has been reported in numerous seismicity studies (Mogi 1962; Scholz 1968; Wyss 1973). In particular, Ogata and Abe (1991) presented time variations in the $b$-value for the entire world, several seismically active regions, and Japan. Nanjo et al. (2012) reported a decrease in the $b$-value before the Great 2011 M9.0 Tohoku Earthquake.

The seismic activity rate $A$ is defined as the number of earthquakes with magnitude greater than or equal to a specified magnitude per specific unit area in a region (Bird et al. 2015). This value is used for construction of maps and showing areas of different seismic intensity. Calculations of earthquake number, cumulative seismic energy, or seismic moment often use methods describing the state of seismicity (Greenhalgh and Singh 1988; Horner 1983; Takahashi and Kasahara 2007).

Direct use of the above-mentioned parameters under some conditions might cause difficulties with respect to the seismicity level representation; For example, seismicity parameter comparison between two different regions requires qualitative assessment of the seismic regime, because the same amount of energy release or seismicity rate might be abnormally high for one region but abnormally low for another. This suggests that use of absolute seismicity parameters is not appropriate in certain situations. Use of the normalized distribution function of the same parameter, however, would overcome this drawback.

The SESL'09 method developed by Saltykov (2011) is designed to represent relative seismicity characteristics using the seismic moment release rate for arbitrary periods. The empirical distribution function of the total seismic moment during a certain time interval is defined as $F\left(M_{0}\right)=P\left(\Sigma M_{0} \leq M_{0}\right)$, where $P$ indicates the probability. If the moment release during a unit interval exceeds a defined threshold $F$, a higher or lower seismicity anomaly is recognized (Figs. 2,3). This procedure can be used to monitor the time evolution of the seismic moment release in a region. The normalized $F$ value also allows direct comparison of the time variation $F$ for two or more different regions, using correlation 


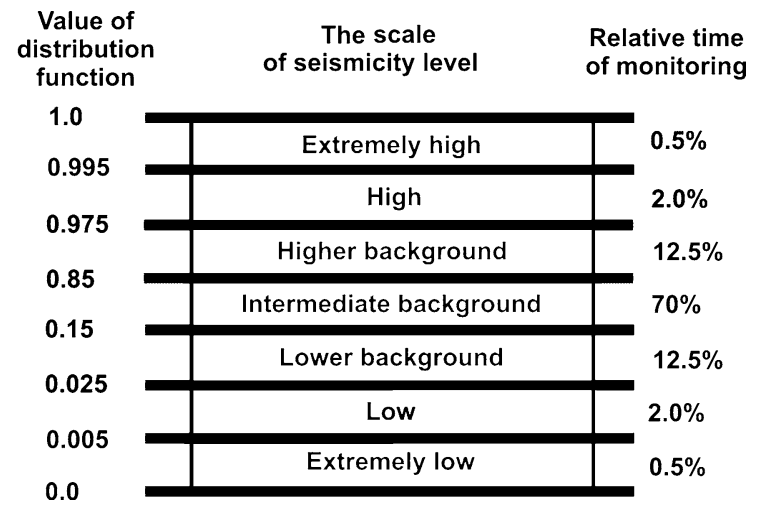

Figure 2

SESL'09 scale

analysis. The result of this method might be affected by the stability of the earthquake magnitude, because the majority of the seismic moment is released by larger earthquakes.

We propose to define the threshold values of the distribution function $F$ as follows: $F=0.005,0.025$, $0.15,0.85,0.975$, and 0.995 (Saltykov 2011). The intervals between these values characterize a scale that contains five seismicity levels (Fig. 2): extremely high, $0.995 \leq F$; high, $0.975 \leq F<0.995$; background, $\quad 0.025<F<0.975$; low, $0.005<F \leq 0.025$; and extremely low, $F \leq 0.005$. These criteria indicate that the background level occurs in $95 \%$, high and low levels occur in $2 \%$, and extremely high/low levels occur in $0.5 \%$ of the monitoring time. The background level can be further divided into three sublevels: lower background, $0.025<F \leq 0.15$; intermediate background, $0.15<F<0.85$; and higher background, $0.85 \leq F<0.975$ (Fig. 2). With this refinement, the intermediate background level will occur in $70 \%$ of the monitoring time, while higher/lower background levels occur in $12.5 \%$ of the time.

To be able to use the scale in practice, the quantiles of the seismic moment distribution corresponding to the threshold values of the probability $F$ for different time intervals should be determined. Using the set of distribution functions $F\left(M_{0}\right)$ for different time intervals $\Delta T$, one can obtain any quantile $M(F)$ as a function of the time window $\Delta T$. The resulting quantiles for a set of $\Delta T$ values are fit with a monotone curve. The set of curves forms a nomogram, which suggests a qualitative seismicity estimate for any specified time interval $\Delta T$.

The SESL'09 methodology can be used to characterize the seismicity of a target area and allows seismologists to study variations in seismicity levels over time. SESL'09 offers an intuitive scale to describe the state of seismicity understandable to a layman. Seismic anomalies such as the quiescence period preceding a strong earthquake can be detected using this method. SESL'09, unlike more complex methods that describe the variations in seismicity in time [e.g., RTL (Sobolev and Tyupkin 1997a; Sobolev et al. 1997) and ETAS (Ogata 1999)], operates with the actual distribution function of seismicity, which makes it a convenient method of study. The SESL'09 method can represent the seismicity level in both real time and retrospectively. Quick estimation and easy operation in routine monitoring are available. The Geophysical Survey of the Russian Academy of Sciences has been testing this method to evaluate the seismicity level in seismic areas and active volcanoes in Kamchatka, Russia.

\section{Results and Discussion}

\subsection{Distribution Functions of Seismic Moment}

The empirical distribution function of the total seismic moment in moving time windows of 7,15 , 30, 90, 180, and 365 days was calculated for each period (Table 1). Figure 3 presents the calculated distribution functions for all data presented in Table 1.

In zone 1, all levels of seismic activity of the SESL'09 were identified in all time windows since 1995. From 1960 to 2013, no extremely low- or lowlevel seismicity was observed in the time windows of 180 and 365 days. An intermediate background seismicity level was detected for time windows of $7,15,30$, and 90 days. No low-level seismicity was observed in 1980-2013 and 1985-2013 in the time windows of 7,15 , and 30 days. These seismicity characteristics are caused by a large number of moving time windows without earthquakes with magnitude above the reliable detection level. 

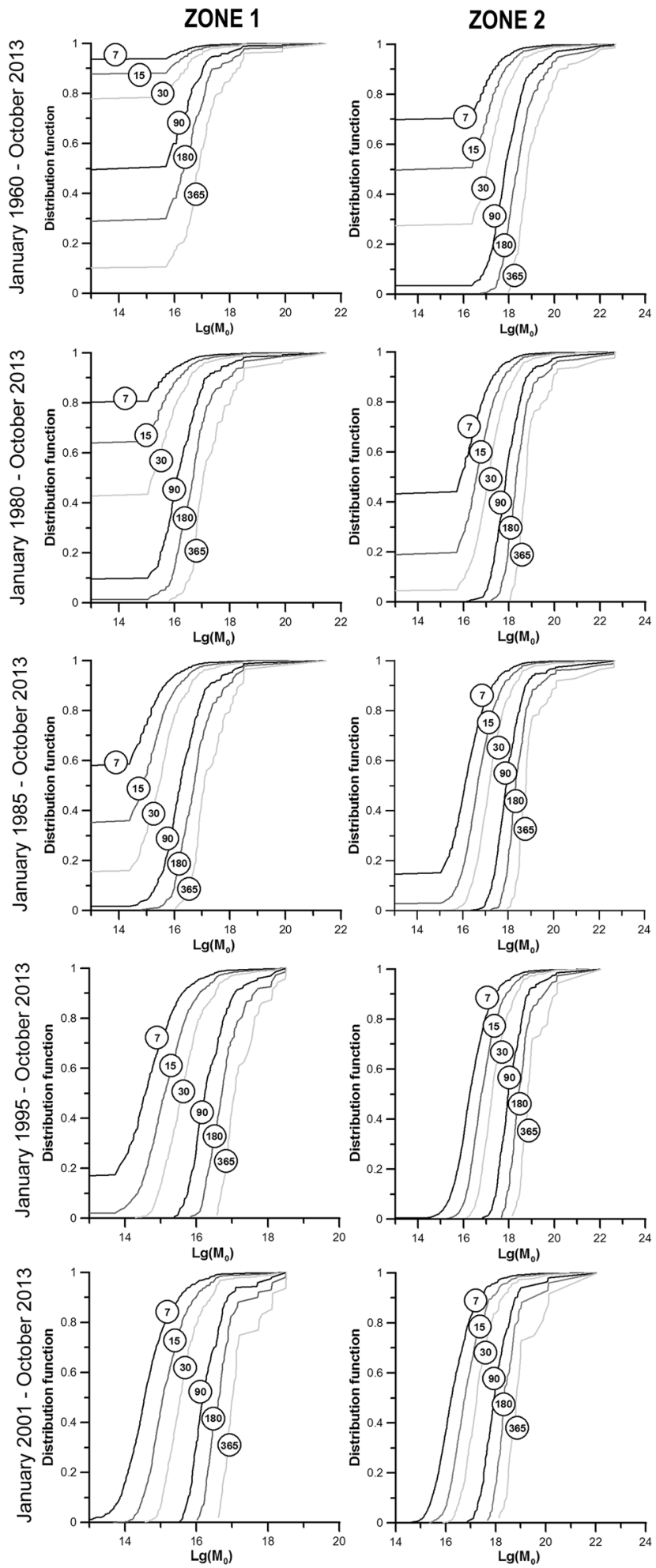

Figure 3

Distribution functions of total seismic moment for zones 1 and 2 in moving time windows of 7, 15, 30, 90, 180, and 365 days for different time periods 
The distribution function for zone 2 in the time window $>90$ days generates the entire seismicity scale starting from 1960 (Fig. 3). For short time windows (7, 15, and 30 days), low-level seismic activity was detectable since 1995 . These results reflect the higher seismicity caused by the different plate convergence rates between zone 1 and zone 2 . Little low-level seismic activity has been observed in longer time windows of 180 and 365 days since 1995, owing to limited time intervals.

Analysis of the constructed distribution functions allowed determination of the optimal time window for the considered time periods (Table 2). The selection criterion was compliance of the distribution function with the maximum number of SESL'09 levels. For each time window, the time period for which the number of time intervals with zero values did not exceed 0.005 (first threshold value of the SESL'09 scale) was selected.

Comparison of the distribution functions for different moving time windows and sampling intervals was performed using the Kolmogorov-Smirnov fitting criterion (Corder and Foreman 2014). This statistical test is used to evaluate whether two empirical functions obey the same probabilistic distribution. The Kolmogorov-Smirnov criterion is nonparametric and sensitive to sampling differences and requires no distribution-type information.

The results of the test for the combination shown in Table 2 suggest that the distribution function of zones 1 and 2 has a high level of significance (5\%) with respect to their statistical difference. Therefore, the seismic process of zone 1 differs from that of zone 2 and is consistent with the crustal convergence in zone 1 and subduction in zone 2 . The same statistical test was performed for each zone using different time intervals and sampling periods. The combinations shown in Table 3 indicate the sampling periods with statistically indistinguishable results. Seismicity in short time windows (7-30 days) should be mostly considered in the 1995-2013 sampling period, whereas seismicity in long time windows (180-365 days) should be considered in the 1960-2013 sampling period.

\subsection{Nomograms of SESL'09}

The changes in seismicity in the study area are described using SESL'09 nomograms. These nomograms can be used to determine the level of seismicity for any time interval if the total seismic moment is known retrospectively. Figure 4 shows the nomograms for zones 1 and 2 constructed in time windows from 5 to 1000 days for the data from 1960 to 2013 and from 1995 to 2013 . The seismicity level is defined as a function of the released total seismic moment (vertical axis) during a time interval (horizontal axis). Recent seismicity levels during an arbitrary period can also be evaluated using nomograms.

Figure 4 shows that the nomogram pattern depends on the selected time period. Seismicity levels below the lower background are absent in the period from 1960 to 2013 in zone 1, and extremely low levels of seismicity are absent in the nomogram of zone 2. This is because there are many time windows without earthquakes. These nomograms characterize the seismicity of the regions and allow formalization of the notion of "seismic background" for different time windows (Table 4).

The criterion for the optimal choice of the time windows matches the size of the time windows to the maximum number of seismicity levels in the SESL'09 nomogram. For zone 1, the period from

Table 2

Time periods that should be used to calculate the distribution function of released seismic moment for selected moving time windows

\begin{tabular}{llr}
\hline Moving time window (days) & Sampling period for zone 1 & Sampling period for zone 2 \\
\hline 7 & January 2001-October 2013 & January 1985-October 2013 \\
15 & January 1995-October 2013 & January 1980-October 2013 \\
30 & January 1995-October 2013 & January 1960-October 2013 \\
90 & January 1980-October 2013 & January 1960-October 2013 \\
180 & January 1960-October 2013 & January 1960-October 2013 \\
365 & January 1960-October 2013 & January 1960-October 2013 \\
\hline
\end{tabular}


Table 3

Sampling periods corresponding to the statistically indistinguishable combination of distribution functions shown in Fig. 3

Zone 1

Time window (days)

Time frame (years)

$P$ value

Zone 2

Time window (days)

Time frame (years)

$P$ value
7

2001-2013

15

1995-2013

0.038
15

1995-2013

0.008

15

1995-2013

0.002
30

1995-2013

0.01

30

1980-2013

0.014

90
$1980-2013$
0.013

180

1980-2013

0.005

$\begin{array}{lll}90 & 180 & 365 \\ 1960-2013 & 1960-2013 & 1960-2013 \\ 0.009 & 0.014 & 0.034\end{array}$

$P$ value parameter specified for the period compared with the previous period

ZONE 1

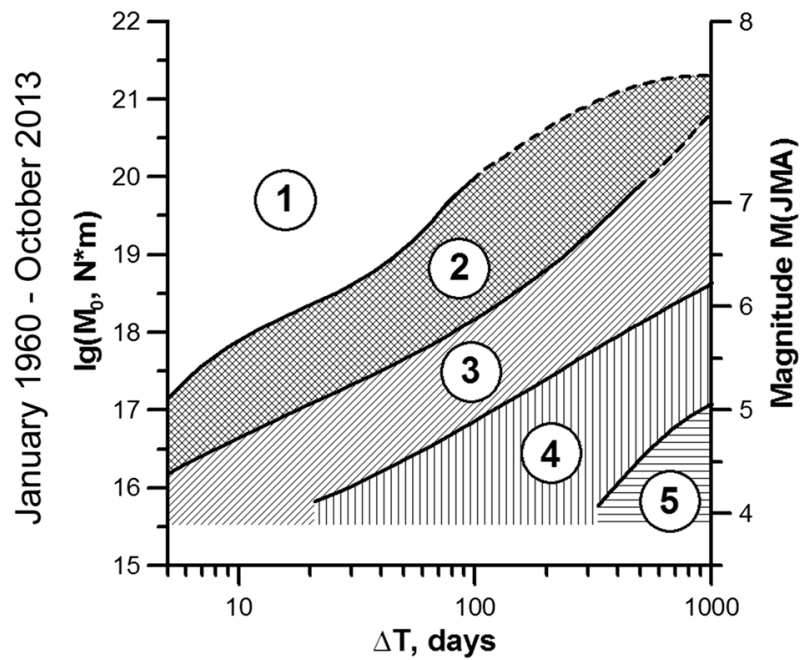

ZONE 1

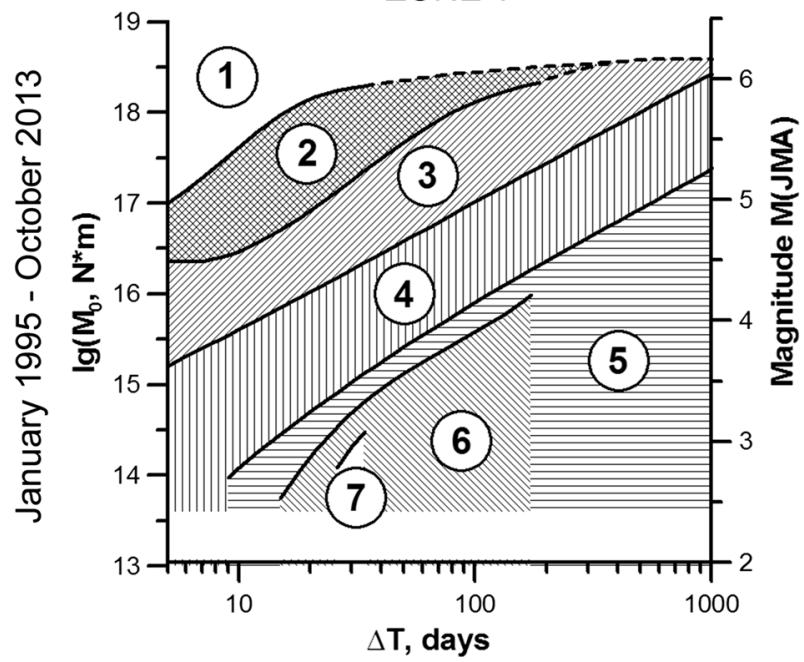

ZONE 2

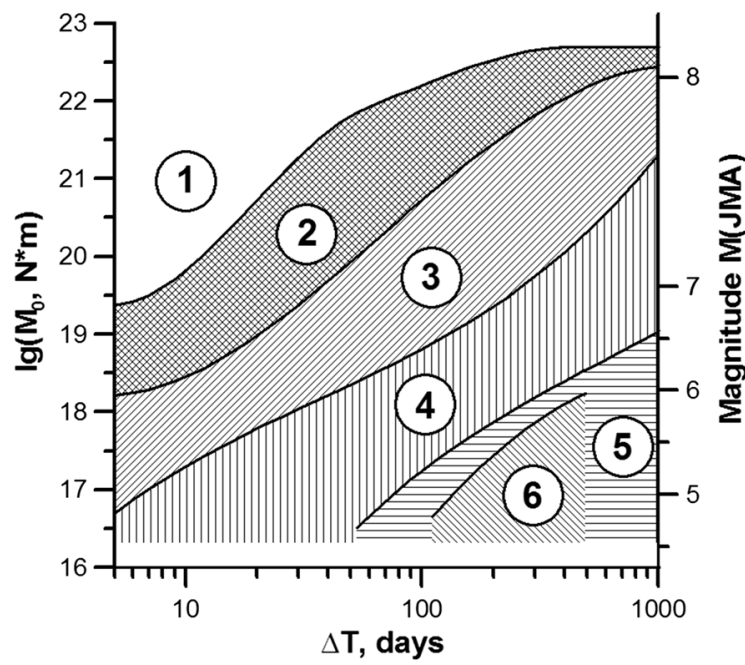

ZONE 2

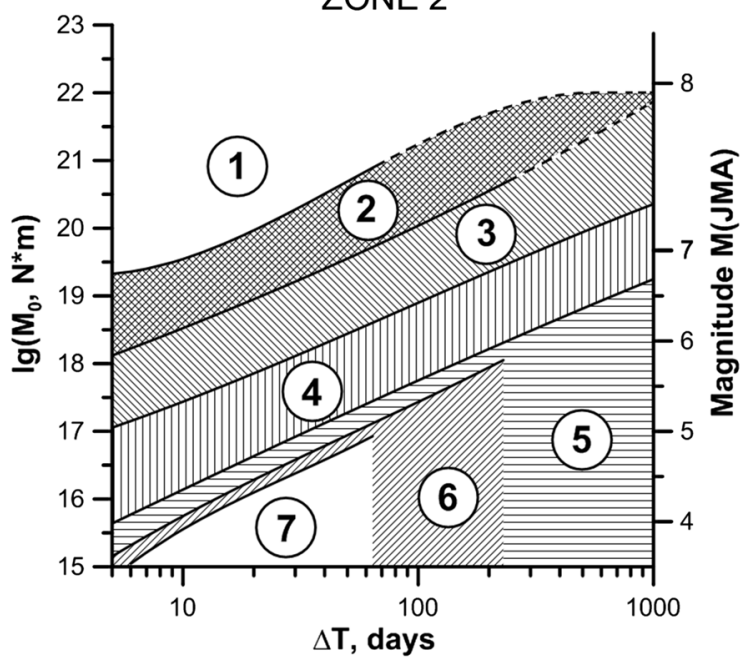

Figure 4

SESL'09 nomograms for zones 1 and 2 for periods 1960-2013 and 1995-2013. The calculation was performed for a set of moving time windows from 5 to 1000 days. The numbers indicate the levels of seismicity based on SESL'09: 1—extremely high, 2-high, 3-higher background, 4-intermediate background, 5-lower background, 6-low, 7-extremely low. Dotted lines indicate areas of extrapolation for extremely high and high seismicity levels 
Table 4

Borders of intermediate background seismicity levels of seismically active zones of Hokkaido for different moving time windows

\begin{tabular}{|c|c|c|c|c|c|c|}
\hline \multirow[t]{2}{*}{ Zone } & \multirow[t]{2}{*}{ Sampling period } & \multirow[t]{2}{*}{$\begin{array}{l}\text { Size of moving time } \\
\text { window (days) }\end{array}$} & \multicolumn{2}{|c|}{$\begin{array}{l}\text { Boundaries of } \log \left(M_{0},[N \times m]\right) \text {, which is } \\
\text { the intermediate background }\end{array}$} & \multicolumn{2}{|c|}{$\begin{array}{l}\text { Boundaries of magnitude } M_{\mathrm{j}} \text {, which is } \\
\text { the intermediate background }\end{array}$} \\
\hline & & & Bottom & Top & Bottom & Top \\
\hline \multirow[t]{6}{*}{1} & \multirow[t]{3}{*}{ January 1960-October 2013} & 7 & - & - & - & - \\
\hline & & 30 & 15.7 & 16.0 & 4.0 & 4.3 \\
\hline & & 365 & 15.9 & 17.9 & 4.2 & 5.6 \\
\hline & \multirow[t]{3}{*}{ January 1995-October 2013} & 7 & 13.7 & 15.4 & 2.5 & 3.8 \\
\hline & & 30 & 15.0 & 16.3 & 3.5 & 4.5 \\
\hline & & 365 & 16.7 & 17.8 & 4.8 & 5.6 \\
\hline \multirow[t]{6}{*}{2} & \multirow[t]{3}{*}{ January 1960-October 2013} & 7 & 16.4 & 17.0 & 4.5 & 5.0 \\
\hline & & 30 & 16.4 & 18.0 & 4.5 & 5.8 \\
\hline & & 365 & 18.3 & 19.9 & 6.0 & 7.1 \\
\hline & \multirow[t]{3}{*}{ January 1995-October 2013} & 7 & 15.9 & 17.2 & 4.2 & 5.3 \\
\hline & & 30 & 16.9 & 18.1 & 4.9 & 5.9 \\
\hline & & 365 & 18.6 & 19.7 & 6.3 & 7.1 \\
\hline
\end{tabular}

1960 to 2013 corresponds to the moving time window range from 331 to 1000 days (represented by five seismicity levels on the SESL'09 scale). For the period from 1995 to 2013, this range is 26-34 days (represented by all seismicity levels on the SESL'09 scale). Similarly, the preferable range for zone 2 from 1960 to 2013 and from 1995 to 2013 is 111-491 days (represented by six levels of seismicity) and 5-64 days, respectively.

Comparison of the constructed nomograms shows the differences in the seismic moment release during all seismicity levels between zones 1 and 2 . In particular, the intermediate background level in zone 2 is higher than in zone 1 in all studied sampling periods (Table 4), reflecting the active tectonics in these regions.

\subsection{Correlation of Seismicity Level Variations in Zones 1 and 2}

The time variations in seismicity levels indicate seismic activity characteristics in the study area. The autocorrelation and cross-correlation functions of the seismicity level were investigated for possible trends or cyclical fluctuations and the spatial correlation of the seismic process in time.

Autocorrelation functions for seismicity levels were calculated for both zones (Fig. 5). The functions depend on the limits of the time window caused by the peculiarities of the values of certain autocorrelation intervals. The autocorrelation calculation should start with a value of the time shift equal to the size of the time window; For example, one should use the autocorrelation function with a 4-week displacement for a time window of 30 days, while the value of the displacement will be 52 weeks for a time window of 365 days.

These autocorrelation functions for zones 1 and 2 show the independence of the current value of the seismicity level from the previous time intervals for all time windows (Fig. 5).

The cross-correlations of all time windows show that the series of time variations in the seismicity level for zones 1 and 2 were uncorrelated in all long time intervals for almost all periods (18 years and over). The correlation between zones 1 and 2 from 1996 to 2000 was stronger. The simultaneous correlation in two independent windows of 90 and 180 days suggests signal confidence (Fig. 6). The maximum correlation coefficient is 0.72 ; a temporal lag of 8 weeks was identified in the 180-day time window. The cross-correlations for the time window of 90 days show the maximum value of 0.53 , with the same time lag. These results suggest that the active manifestation of seismicity in zone 2 from 1996 to 2000 was 8 weeks ahead of the seismic activity in zone 1 . 

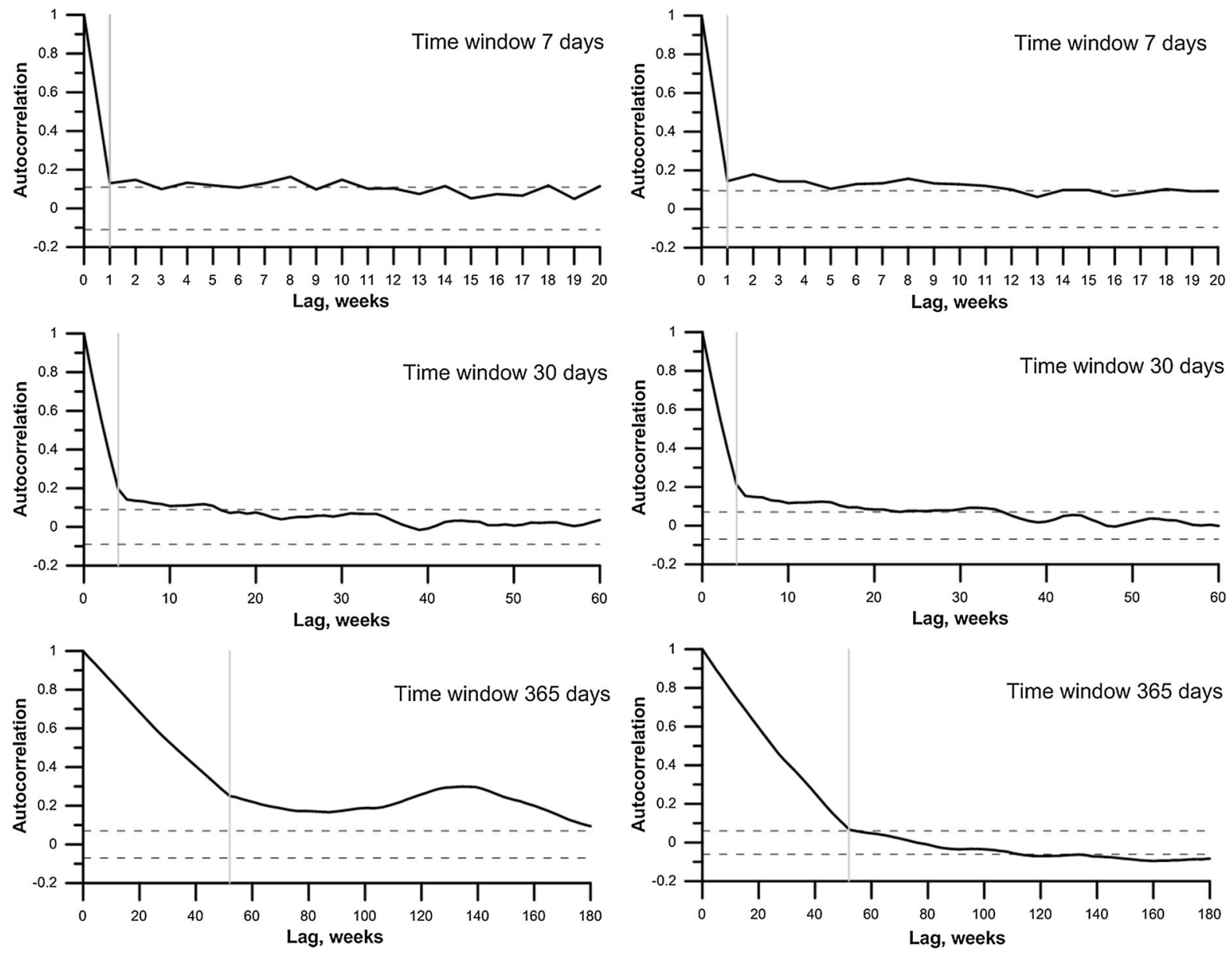

Figure 5

Autocorrelation function for zones 1 and 2 plotted for time windows of 7, 30, and 365 days. The vertical gray line indicates the border of the temporal offset, which is a function of the autocorrelation, and depends on the previous time intervals based on the choice of the time window. Dashed lines indicate $99 \%$ confidence bands

\subsection{Seismic Quiescence prior to Hokkaido Toho-Oki Earthquake $\left(M_{j} 8.2\right)$}

The Hokkaido Toho-Oki Earthquake of $M_{\mathrm{j}} 8.2$ occurred in the southern part of the Kurile Islands on 4 October 1994. It was an intraslab earthquake and the strongest earthquake in zone 2 during the study period, causing extremely high-level aftershock seismicity. The time evolution of the seismicity level in zone 2 is shown in Fig. 7. The seismicity in the time window of 365 days in zone 2 mostly correlates with the intermediate background level. The seismicity decreased to a low level in 6 months before this earthquake. This is the longest seismicity level decrease in the whole study period (1960-2013) and suggests a seismic quiescence period prior to this great earthquake.

Pre-earthquake seismic quiescence periods have been reported in previous studies (Saltykov and Kugaenko 2000; Sobolev and Tyupkin 1997b; Wiemer and Wyss 1994; Wyss 1986; Wyss et al. 2004). Katsumata and Kasahara (1999) described seismic quiescence around the focal area of this 1994 great earthquake, and indicated approximately 5 years of quiescence preceding the main shock. Takanami et al. (1996) also suggested 3 years of precursory seismic quiescence near the focal region. These three independent research results lead to the same conclusion of seismic quiescence prior to this 


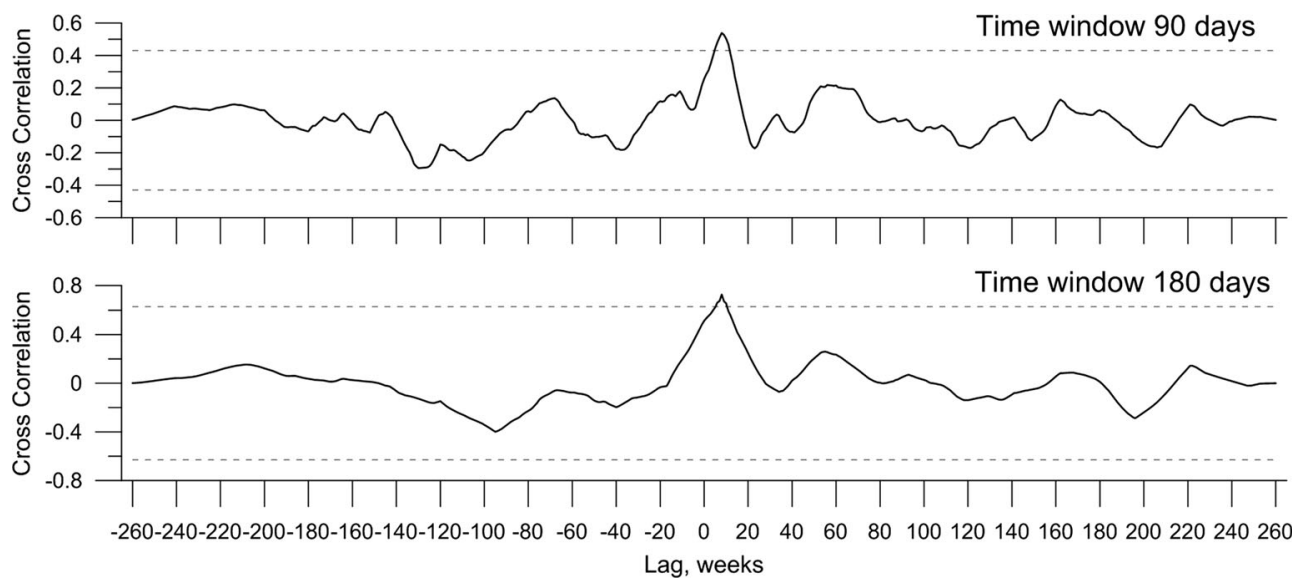

Figure 6

Cross-correlation functions between the series of time variations of the seismicity level in zones 1 and 2 for time windows of 90 and 180 days from 1996 to 2000. These functions take the maximum value at the temporal lag of 8 weeks. Dashed lines indicate $95 \%$ confidence bands

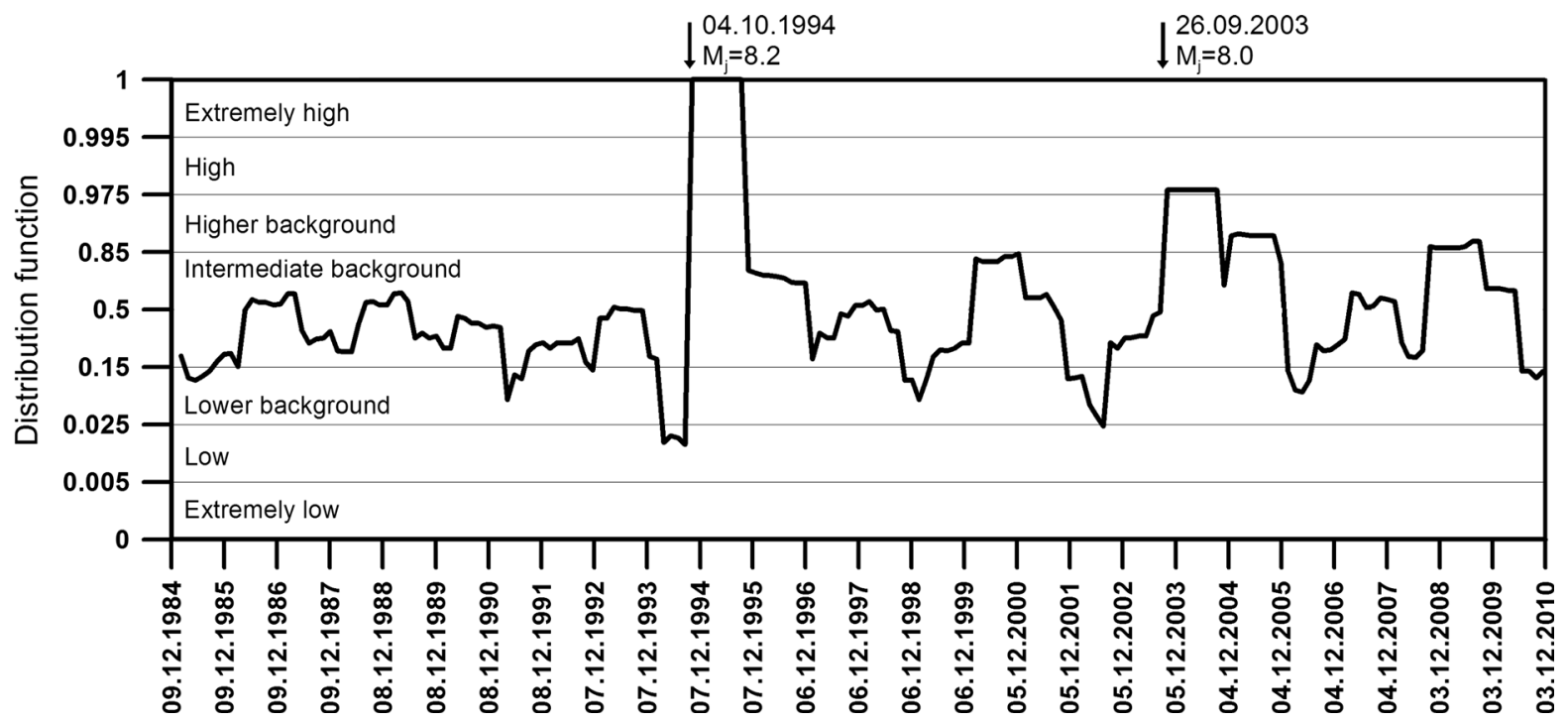

Figure 7

Variations in seismicity level in zone 2 from November 1985 to December 2010. Moving time window: 365 days. Arrows indicate the $M_{\mathrm{j}}=8.2$ Hokkaido Toho-Oki Earthquake on 4 October 1994, and $M_{\mathrm{j}}=8.0$ Tokachi-Oki Earthquake on 26 September 2003

earthquake. This also indicates the validity of the SESL'09 procedure.

The difference in the duration of the seismic quiescence between this study and two previous studies, by Takanami et al. (1996) and Katsumata and Kasahara (1999), is likely caused by the differences in the areas analyzed; Zone 2, in this study, covers a wider region than the aftershock region of the earthquake investigated by Katsumata and Kasahara
(1999). This seismic quiescence was not observed earlier than 6 months before the main shock because a significant number of earthquakes outside the aftershock region within zone 2 did not allow the level of seismicity to decrease below the intermediate background. The reliability of this quiescence period can be confirmed using the results from independent analyses. 
Seismic quiescence was not observed prior to other strong earthquakes in zones 1 and 2; For example, the seismicity in the time window of 365 days preceding the $M_{\mathrm{j}} 8.0$ Tokachi-Oki Earthquake on 26 September 2003 was within the intermediate background level and increased to the high level after the earthquake due to the aftershock activity (Fig. 7).

\section{Conclusions}

The SESL'09 methodology was applied to describe the seismically active areas of Hokkaido. The seismic catalog of the Japanese Meteorological Agency was evaluated. Two seismic zones in Hokkaido, on the Sea of Japan and Pacific sides, were selected for the study. Five periods with uniform earthquake detectability based on the GutenbergRichter relationship were investigated.

Statistical analysis of the seismic activity level using the Kolmogorov-Smirnov criterion suggested different distribution functions for the released seismic moment on the Sea of Japan and Pacific sides. The optimal time window for analysis was also estimated using this statistical criterion. Analysis of time variations in seismicity levels showed no correlation between the seismic processes of the two studied zones in the target period. However, a strong correlation with time lag of 8 weeks was identified between 1996 and 2000.

A seismic quiescence period was identified before the $M_{\mathrm{j}} 8.2$ Hokkaido Toho-Oki Earthquake on 4 October 1994. This quiescence period correlates to the 6-month decrease in the seismicity on the Pacific side to a lower level prior to the earthquake and might be a reliable precursor signal because similar quiescence characteristics were detected by independent seismicity analyses (Takanami et al. 1996; Katsumata and Kasahara 1999).

\section{Acknowledgements}

The hypocenters were determined by the Japan Meteorological Agency in collaboration with the Ministry of Education, Culture, Sports, Science, and
Technology (MEXT) using seismic wave data provided by cooperating organizations including Hokkaido University, Hirosaki University, Tohoku University, University of Tokyo, Nagoya University, Kyoto University, Kochi University, Kyushu University, Kagoshima University, the National Research Institute for Earth Science and Disaster Resilience (NIED), the Nat. Inst. Adv. Ind. Sci. Tech. (AIST), Tokyo Metropolitan Government, Shizuoka Pref., Hot Springs Res. Inst. Kanagawa Pref., Yokohama City, GSI, and JAMSTEC. This research was supported by JSPS KAKENHI (25257204) and MEXT under the Earthquake and Volcano Hazards Observation and Research Program. We thank anonymous reviewers for their constructive comments that greatly improved this manuscript.

Open Access This article is distributed under the terms of the Creative Commons Attribution 4.0 International License (http:// creativecommons.org/licenses/by/4.0/), which permits unrestricted use, distribution, and reproduction in any medium, provided you give appropriate credit to the original author(s) and the source, provide a link to the Creative Commons license, and indicate if changes were made.

\section{REFERENCES}

Aki, K. (1965). Maximum likelihood estimate of $b$ in the formula $\log N=a-b M$ and its confidence limits. Bulletin of the Earthquake Research Institute, University of Tokyo, 43, 237-239.

Bird, P. (2003). An updated digital model of plate boundaries. Geochemistry, Geophysics, Geosystems, 4, 1027. https://doi.org/ 10.1029/2001GC000252.

Bird, P., Jackson, D. D., Kagan, Y. Y., Kreemer, C., \& Stein, R. S. (2015). GEAR1: A global earthquake activity rate model constructed from geodetic strain rates and smoothed seismicity. Bulletin of the Seismological Society of America, 105, 2538-2554. https://doi.org/10.1785/0120150058.

Corder, G. W., \& Foreman, D. I. (2014). Nonparametric statistics: A step-by-step approach (2nd ed.). New Jersey: Wiley.

DeMets, C., Gordon, R. G., \& Argus, D. F. (2010). Geologically current plate motions. Geophysical Journal International, 181, $1-80$.

Greenhalgh, S. A., \& Singh, R. (1988). The seismicity of the Adelaide geosynclines, South Australia. Bulletin of the Seismological Society of America, 78, 243-263.

Gusev, A. A., \& Mel'nikova, V. N. (1990). Relations between magnitudes-world average and for Kamchatka. Volcanology and Seismology, 6, 55-63.

Gutenberg, B., \& Richter, C. F. (1949). Seismicity of the earth and associated phenomena. Princeton: Princeton University Press. 
Horner, R. B. (1983). Seismicity in the St. Elias region of northwestern Canada and southeastern Alaska. Bulletin of the Seismological Society of America, 73, 1117-1137.

Katsumata, K., \& Kasahara, M. (1999). Precursory seismic quiescence before the 1994 Kurile Earthquake $(M \mathrm{w}=8.3)$ revealed by three independent seismic catalogs. Pure and Applied Geophysics, 155, 443-470.

Mogi, K. (1962). Magnitude-frequency relation for elastic shocks accompanying fractures of various materials and some related problems in earthquakes (2nd paper). Bulletin of the Earthquake Research Institute, University of Tokyo, 40, 831-883.

Nanjo, K. Z., Hirata, N., Obara, K., \& Kasahara, K. (2012). Decade-scale decrease in b value prior to the M9-class 2011 Tohoku and 2004 Sumatra quakes. Geophysical Research Letters, 39, L20304. https://doi.org/10.1029/2012GL052997.

Ogata, Y. (1999). Seismicity analysis through point-process modeling: A review. Pure and Applied Geophysics, 155, 471-507.

Ogata, Y., \& Abe, K. (1991). Some statistical features of the longterm variation of the global and regional seismic activity. International Statistical Review, 59, 139-161.

Saltykov, V. A. (2011). A statistical estimate of seismicity level: The method and results of application to Kamchatka. Volcanology and Seismology, 5, 123-128.

Saltykov, V. A., \& Kugaenko, Yu A. (2000). Seismic quiescences before two large Kamchatka earthquakes of 1996. Volcanology and Seismology, 22, 87-98.

Scholz, C. H. (1968). The frequency-magnitude relation of microfracturing in rock and its relation to earthquakes. Bulletin of the Seismological Society of America, 58, 399-415.

Sella, G. F., Dixon, T. H., \& Mao, A. (2002). REVEL: a model for recent plate velocities from space geodesy. Journal of Geophysical Research, 107, B4. https://doi.org/10.1029/ 2000JB000033.

Sobolev, G. A., \& Tyupkin, Y. S. (1997a). Low-seismicity precursors of large earthquakes in Kamchatka. Volcanology and Seismology, 18, 433-446.
Sobolev, G. A., \& Tyupkin, Y. S. (1997b). RTL prognostic parameter for strong earthquakes. The 29th General Assembly of the Intern. Assoc. of Seismology and Physics of the Earth's Interior: Abstracts. Thessaloniki, Greece. p. 143.

Sobolev, G. A., Tyupkin, Y. S., Zavyalov, A. D. (1997). Map of expected earthquakes algorithm and RTL prognostic parameter: Joint application. The 29th General Assembly of the Intern. Assoc. of Seismology and Physics of the Earth's Interior: Abstracts. Thessaloniki, Greece. p. 97.

Takahashi, H., \& Kasahara, M. (2007). Spatial relationship between interseismic seismicity, coseismic asperities, and aftershock activity in the southwestern Kuril Islands. In J. Eichelberger (Ed.), Volcanism and subduction: The Kamchatka region (pp. 153-164). Washington: American Geophysical Union.

Takanami, T., Sacks, I. S., Snoke, J. A., Motoya, Y., \& Ichiyanagi, M. (1996). Seismic quiescence before the Hokkaido-Toho-Oki earthquake of October 4, 1994. Journal of Physics of the Earth, 44, 193-203.

Wiemer, S., \& Wyss, M. (1994). Seismic quiescence before the landers $(M=7.5)$ and big bear $(M=6.5) 1992$ earthquakes. Bulletin of the Seismological Society of America, 84, 900-916.

Wyss, M. (1973). Towards a physical understanding of the earthquake frequency distribution. Geophysical Journal of the Royal Astronomical Society, 31, 341-359.

Wyss, M. (1986). Seismic quiescence precursor to the 1983 Kaoiki $(M \mathrm{~s}=6.6)$, Hawaii, earthquake. Bulletin of the Seismological Society of America, 76, 785-800.

Wyss, M., Sobolev, G., \& Clippard, J. D. (2004). Seismic quiescence precursors to two M7 earthquakes on Sakhalin Island, measured by two methods. Earth Planets Space, 56, 725-740.

Zonenshain, L. P., \& Savostin, L. A. (1981). Geodynamics of the Baikal rift zone and plate tectonics of Asia. Tectonophysics, 76, $1-45$. 